\title{
Awareness and Attitude About Prenatal Sex Determination and the Preconception and Prenatal Diagnostic Techniques Act Among Pregnant Women Attending the Antenatal Clinic
}

\author{
1Jwal M Banker, ${ }^{2}$ Uday J Patel, ${ }^{3}$ Viral S Modi, ${ }^{4}$ Bakul R Leuva
}

\begin{abstract}
Introduction: Preconception and prenatal diagnostic techniques (PCPNDT) Act 1994, was put into effect and was further amended in 2003 for improving the sex ratio in our country. But even after its introduction, there has been no improvement in the sex ratio. We conducted this study to find out the awareness and attitude of the "end user" - the pregnant patient - towards it and to know whether this Act was really the answer to the problem.

Aim: To know the awareness and attitude of the women regarding the PCPNDT Act.

Method: This cross-sectional study was carried out in the antenatal clinic of Dhiraj Hospital, Vadodara which is a tertiary care hospital. A total of 1000 Pregnant women attending the Obstetrics out outpatient department (OPD) during the study period of 3 months were given pre-tested semi-structured multiple-choice questionnaires. Data collected was analysed.

Results: A total of $91.2 \%$ of women were aware about the PCPNDT Act. $12.7 \%$ wanted to know the sex of their child and of those, $12.6 \%$ were willing for feticide in case of a female child. None of the nulliparous women wanted sex determination. Total $8.9 \%$ women wanted a male child and the main cause was family pressure $(67.4 \%)$. If sex determination was made legal, $7.3 \%$ more women wanted sex determination. $85 \%$ women believed that doctor and patient both were liable to be punished if found guilty.
\end{abstract}

Conclusion: There is considerable awareness about PCPNDT Act but the Act has failed to fulfil its purpose as it ignores social pressures. We must raise the status of women in society and change mentality of the people.

Keywords: Feticide, Male preference, Preconception and prenatal diagnostic techniques (PCPNDT) Act, Sex ratio

How to cite this article: Banker JM, Patel UJ, Modi VS, Leuva BR. Awareness and Attitude About Prenatal Sex Determination and the Preconception and Prenatal Diagnostic Techniques Act Among Pregnant Women Attending the Antenatal Clinic. J South Asian Feder Obst Gynae 2018;10(3):199-203.

\footnotetext{
${ }^{1,3}$ Resident, ${ }^{2}$ Professor, ${ }^{4} \mathrm{HOD}$ and Professor

${ }^{1-4}$ Department of Obstetrics and Gynaecology, Dhiraj Hospital, Smt. BK Shah Medical Institute and Research Centre, Sumandeep Vidyapeeth, Vadodara, Gujarat, India

Corresponding Author: Jwal M. Banker, Resident, Department of Obstetrics and Gynaecology, Dhiraj Hospital, Smt. BK Shah Medical Institute and Research Centre, Sumandeep Vidyapeeth, Vadodara, Gujarat, India, Mobile: +919723453606, e-mail: jwalbanker@gmail.com
}

Source of support: Nil

Conflict of interest: None

Date of received: 05/07/2017

date of acceptance: 10/08/2018

Date of publication: December 2018

\section{INTRODUCTION}

The sex ratio in India started showing gradual signs of decrease after Independence. ${ }^{1}$ The child sex ratio in India has fallen to 914 females to 1,000 male subjects, the lower most since Independence in the 2011 census report, ${ }^{1}$ indicating a continuing preference for boys. Birth of a female child in India is perceived by many as a curse with economic and social liability. Female feticide, male child preference, and gender inequities are to be blamed for this altered sex ratio. It is believed that the use of modern ultrasound for pre-natal sex determination has led to female sex-selective abortions contributing to the decline in female sex ratio.

There was an urgent need to both, regulate this by a law and to expand the awareness about female feticide to the general population so that people will recognize it as a social issue.

The PCPNDT (Prohibition of sex selection) Act 1994, was put into effect and was further amended in $2003 .{ }^{2}$ The objective of the act was to prevent the misuse of diagnostic techniques in sex detection and sex-selective abortions. Mass media was used to spread the awareness to the people.

However, even after the introduction of this PCPNDT Act, there has been no improvement in the sex ratio. It is critical to find out the reasons behind this-is it related to lack of awareness of the law or implementation of the law or attitude of the society? What is the real problem for this gender disparity?

We conducted this study to find out the awareness and attitude of the "end user"-the pregnant patient-towards gender inequality and the PCPNDT law formulated to address it.

Another question is whether the PCPNDT Act is needed? 
AIM

To know the awareness and the attitude of antenatal patients regarding sex selection and the PCPNDT Act.

\section{METHOD}

This cross-sectional study was carried out in the antenatal clinic of Dhiraj Hospital, Vadodara, from 1st February 2017 to 30th April 2017.

All pregnant women attending the obstetrics and gynaecology OPD during the study period of 3 months were included in the study. All non-pregnant women and relatives were excluded.

One thousand pregnant women attending the antenatal clinic were given pre-tested semi-structured multiple-choice questionnaires. The data collected was then analyzed.

\section{RESULTS}

The study population composition is as shown in Table 1.

\section{(a) Awareness of the Law}

- In this study, out of 1000 women, 912 women were aware of the PCPNDT Act (91.2\%) (Fig. 1)

- Eight hundred twenty-four of these women believed that females did not enjoy equal rights as males in the society $(82.4 \%)$.

\section{(b) The desire to know the sex of the child}

- Even in the present scenario, 127 women (12.7\%) wanted to know the sex of their child. Of those 127 women, 16 women $(12.6 \%)$ told that they would terminate the pregnancy if they found out they had a female child.

Furthermore, of those 16 women, 15 (93.75\%) had 2 or more previous female children.

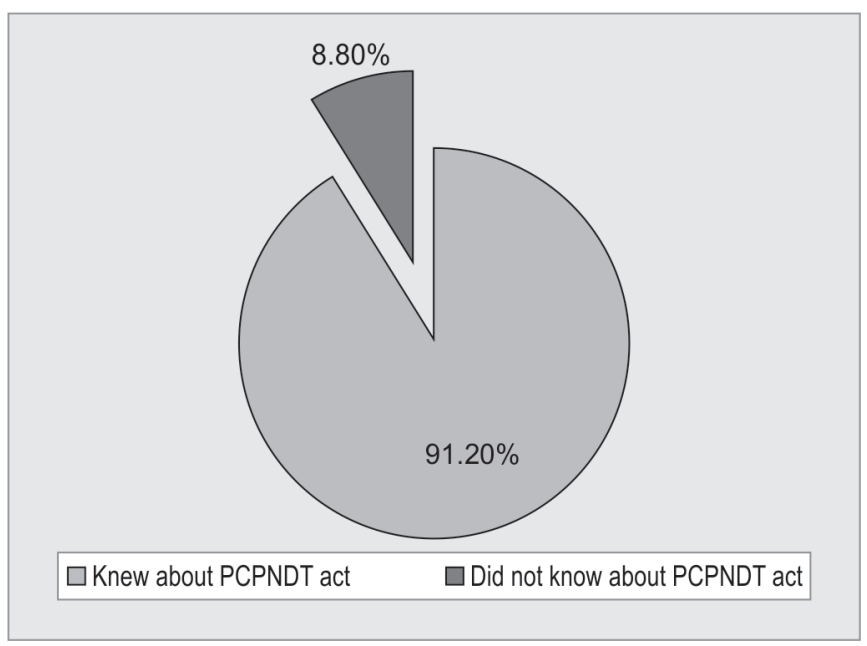

Fig. 1: Awareness about the PCPNDT act in study population
Table 1: Study population characteristics.

\begin{tabular}{lll}
\hline Variable & Total & Percent \\
\hline Age & & \\
$<25$ years & 479 & 47.9 \\
$>25$ years & 521 & 52.1 \\
Education & & \\
$<10$ th Standard & 880 & 88 \\
$>$ 10th Standard & 120 & 12 \\
Occupation & & \\
Housewife & 951 & 95.1 \\
Working & 49 & 4.9 \\
Previous birth of a female child & & \\
Yes & 390 & 39 \\
No & 610 & 61 \\
Religion & & \\
Hindu & 641 & 64.1 \\
Muslim & 259 & 25.9 \\
Sikh & 55 & 5.5 \\
Christian & 45 & 4.5 \\
Parity & & \\
Nullipara & & \\
Multipara & 298 & $29.8 \%$ \\
\end{tabular}

- In this study, out of 1000 women, 298 were nullipara women. Out of these 298 women, 23 women (7.7\%) had male preference, but none of these patients wanted to know the sex of their child or were willing for termination.

- Out of 1000 women, 390 women had 1 or more previous female children.

Of those, 75 women (19.2\%) wanted to know the sex of their child during pregnancy.

Of those women, $37(9.5 \%)$ preferred a male child over a female child.

The male preference in our study according to different variable is as shown in Table 2.

Table 2: Study population characteristics for male child preference

\begin{tabular}{llll}
\hline Variable & Total & $\begin{array}{l}\text { Male Prefer- } \\
\text { ence }\end{array}$ & Percentage \\
\hline $\begin{array}{l}\text { Education } \\
\text { < 10th Standard }\end{array}$ & 880 & 81 & $9.2 \%$ \\
> 10th Standard & 120 & 8 & $6.6 \%$ \\
$\begin{array}{l}\text { Occupation } \\
\text { Housewife }\end{array}$ & 951 & 86 & $9.0 \%$ \\
Working & 49 & 3 & $6.1 \%$ \\
$\begin{array}{l}\text { Previous birth of a } \\
\text { female child }\end{array}$ & & & \\
Yes & 390 & 37 & $9.5 \%$ \\
No & 610 & 52 & $8.5 \%$ \\
Religion & & & \\
Hindu & 641 & 56 & $8.7 \%$ \\
Muslim & 259 & 25 & $9.7 \%$ \\
Sikh & 55 & 4 & $7.2 \%$ \\
Christian & 45 & 4 & $8.9 \%$ \\
\hline
\end{tabular}




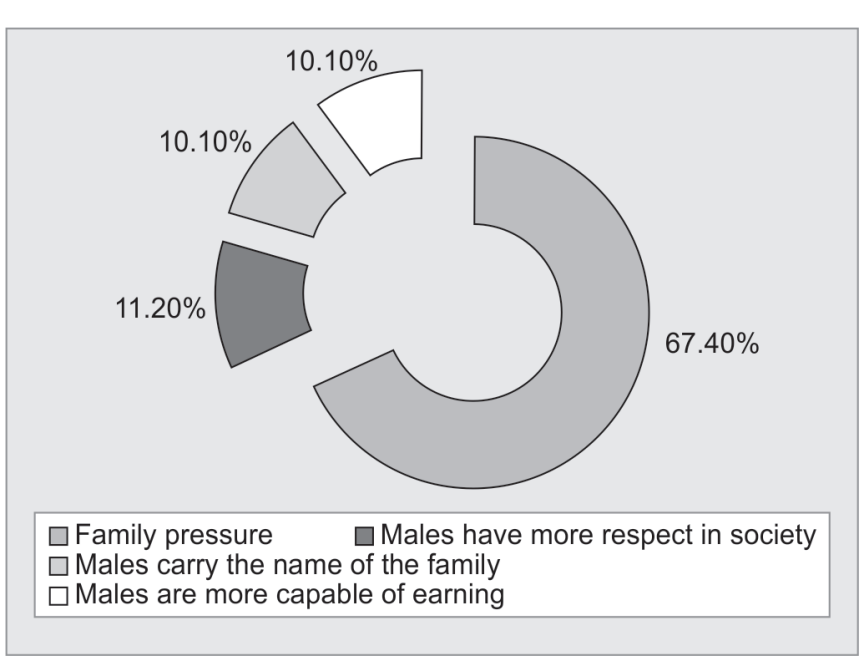

Fig. 2: Reason for male child preference over female child

\section{Reason for Preference for a Male Child}

Out of 1000 women, 89 women (8.9\%) preferred a male child over a female child (Fig. 2). Of these 89 women:

- Sixty women wanted due to family pressure (67.4\%).

- Ten women preferred a male child as they believed that males have more respect in society $(11.2 \%)$.

- Nine women preferred a male child as males carry the name of the family $(10.1 \%)$.

- Nine women preferred a male child as they are more capable of earning (10.1\%).

\section{Willingness for Antenatal Sex Determination}

- Out of the 1000 antenatal women, 107 women (10.7\%) having previous female children told that they would continue to conceive until they get a male child.

Of those women, 32 (29.9\%) wanted sex determination and of those 32 women; 22 women (20.6\%) were willing for feticide.

So overall incidence of willingness for female feticide was $2.2 \%$.

- If sex determination was made legal, 64 more women $(7.3 \%)$ wanted to go for sex determination.

Hence, the desire and willingness for knowing the sex of the child were present in $127+64=191(19.1 \%)$ women.

\section{Penalties of the PCPNDT Act}

Nine hundred and twelve women of the 1000 women knew about the PCPNDT Act and when asked about who is punishable under the Act:

- Eighty-two believed that only the doctor is liable to be punished (9\%)

- Six believed that only the patient is liable to be punished $(0.7 \%)$

- Seven hundred and seventy-six believed that both the doctor and patient are liable to be punished (85\%)

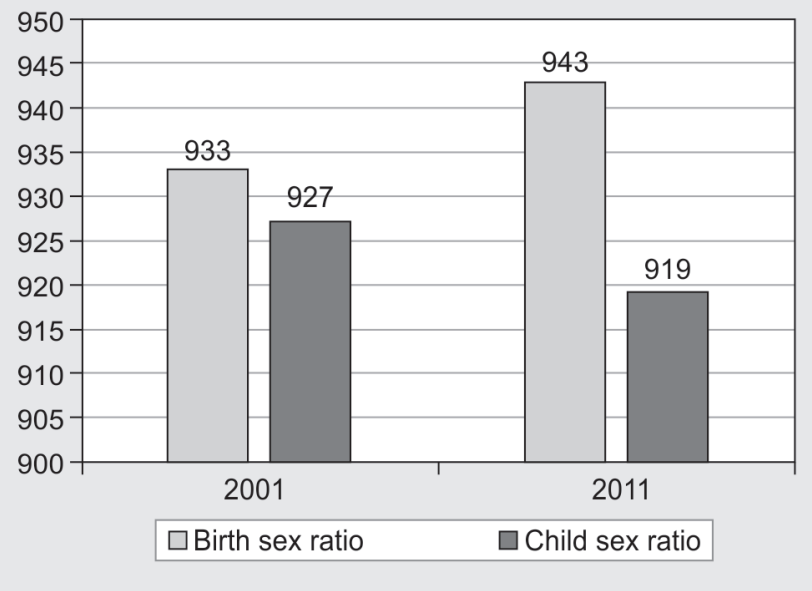

Fig. 3: Comparison of birth and child sex ratios for the census year 2001 and 2011

- Five believed that none are punished (0.5\%)

- Forty-three did not know who is punished (4.7\%)

Out of all 1000 women, 815 women (81.5\%) believed that the doctor doing sex determination should not be punished as strictly as he is being punished now.

\section{DISCUSSION}

After independence, in 1951, our sex ratio at birth was 941 females per 1000 males. ${ }^{1}$

As per the 2011, census sex ratio at birth was 943 per 1000 male and the child sex ratio (0-6 year) was 919 girls per 1000 boys in India. This sex ratio is lowest since independence. ${ }^{1}$

According to the 2001 census, the birth sex ratio was 933, and the child sex ratio was 927. Even though the birth sex ratio has increased from 2001, the child sex ratio shows a decline ${ }^{1}$ (Fig. 3).

Sex Ratios of other places according to their latest census report is as shown in Table 3.

This shows that even though the birth sex ratios do not show much difference, the total sex ratios are considerably different.

This might suggest that nature controls the sex ratio according to the socio-political condition of that region. Is there a need to interfere?

In this study, we came to know that majority of the women $(91.2 \%)$ were aware regarding the PCPNDT Act.

In this study, only $12.7 \%$ (127) women wanted to know the sex of their child. Of those women, only $12.6 \%$ (16)

Table 3: Birth and total sex ratio in different countries

\begin{tabular}{lll}
\hline & Birth sex ratio & Total sex ratio \\
\hline India & 943 & 926 \\
USA & 952 & 1031 \\
UAE & 952 & 459 \\
World & 935 & 1000 \\
\hline
\end{tabular}



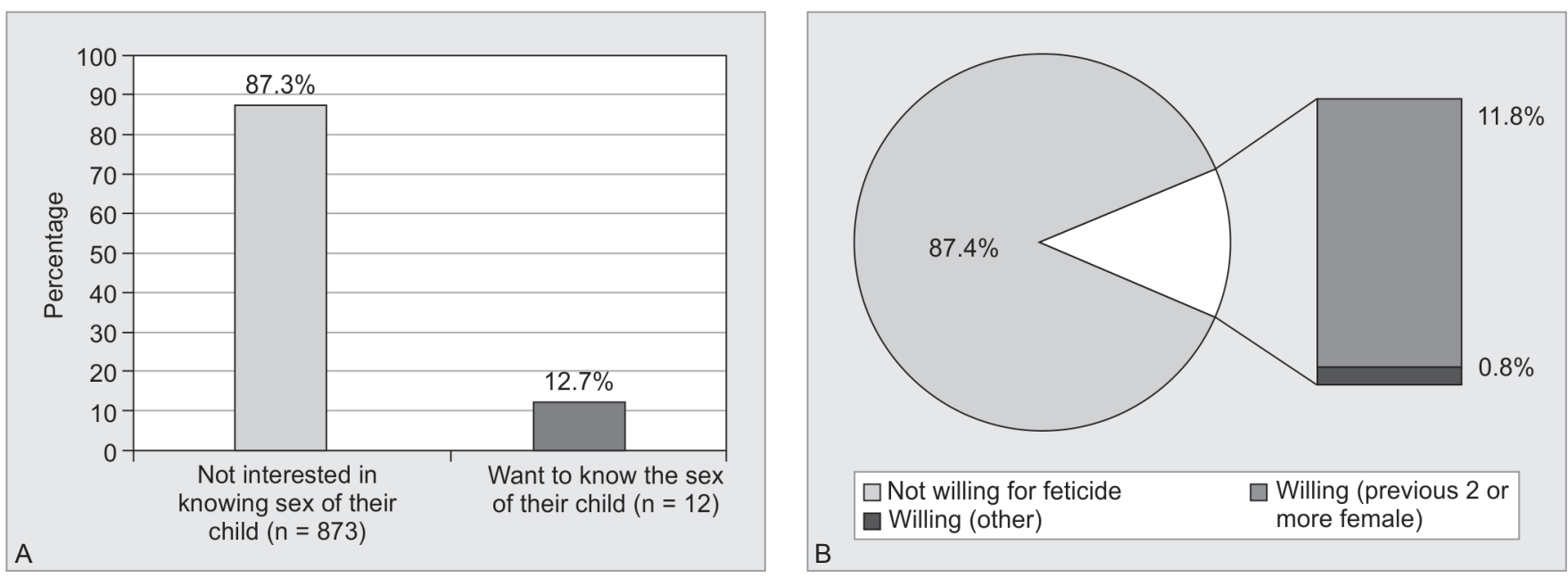

Figs 4A and B: (A) Interest of the women in knowing the sex of their child (total number of women =1000); (B) Willingness of undergoing feticide for women interested in sex determination (total $n=127$ )

women were willing to terminate the pregnancy if they had a female child. Of those 16 women, 15 women had previous two or more female children. So most of the women did not have any preference for the sex of their child, and of those who preferred a male child, all had previous female children. Most patients willing for the termination of a female fetus had two or more previous female children (Fig. 4).

In this study, even though $7.7 \%$ of women who were nullipara preferred a male child, none of them wanted sex determination, and none wanted feticide in the case of a female child.

So this means that nullipara women themselves are not under significant family pressure for a male child or do not themselves wish for male children.

In this study, $39 \%$ of the women had a previous female child. Out of the 75 women (19.2\%) wanted to know the sex of their child but $60 \%$ of those women were willing to continue the pregnancy even if they get a female child.

This means that even with a previous female child, they wish for a male but do not reject female children. This indicates an increasing awareness of female empowerment among the women.

In this study, when asked about the reason for male preference, it was mainly due to family pressure $(67.4 \%)$. But, in nearly every case, the reason for male preference was due to social pressures. This PCPNDT Act fails to take into consideration the social stigma on the people with no male children.

In this study, $10.7 \%$ of women told that they would continue to conceive until they get a male child. This will increase the population, decreased care of their children and more burden on the society and family.

In a study done by Vijayan Sharmila and Thirunavukkarasu Arun Babu regarding the knowledge and awareness about prenatal sex determination and the PCPNDT
Act among pregnant women in the South Indian union territory of Puducherry, $68 \%$ of the women knew about the PCPNDT Act, and $84.3 \%$ knew that prenatal sex determination was a punishable offense. About $79.7 \%$ of women wanted to know the sex of their child and 55.5\% preferred to deliver a male child. $64.1 \%$ of the women believed that prenatal sex determination should not be a punishable offense. ${ }^{3}$

In another study done by Dr. Mehta and Aarti Acharya regarding the attitude, awareness and practice on female feticide of pregnant women in Bikaner, Rajasthan, 77.5\% of women knew that prenatal sex determination could be done while $67.5 \%$ women were unaware about the PCPNDT Act. About $88.5 \%$ women believed that females did not enjoy equal rights as males and $70 \%$ women would try for a male child if their family was complete with a girl child. ${ }^{4}$

The sex ratio of different states in India is as shown in Table $4 .^{1}$

This reflects the aspiration of the people among different parts of India. Does literacy have more impact over the sex ratios?

Section 24 of the PCPNDT Act, 1994 ensures that the court presumes a pregnant woman is compelled by her husband and relatives to undergo sex determination unless proven otherwise. Section 23(3) of the same law states that a woman who is compelled to

Table 4: Comparison of sex ratio of different states of India for the census 2001 and 2011

\begin{tabular}{lll}
\hline & 2001 census & 2011 census \\
\hline Gujarat & 921 & 918 \\
Kerala & 1058 & 1084 \\
Rajasthan & 922 & 926 \\
Tamil Nadu & 986 & 995 \\
Bihar & 921 & 916 \\
West Bengal & 934 & 947 \\
\hline
\end{tabular}


undergo sex selection is not liable for punishment under the Act.

So the women do find a way to know the sex of her child and the doctor gets punished for it.

According to the Lok Sabha unstarred question no. 1116, to be answered on 21st July 2017, a total of 1762 ultrasonography (USG) machines have been sealed and seized, 2371 court cases have been filed, and 416 convictions have so far been secured. Following conviction, the medical licenses of 114 doctors have been suspended/ canceled.

So in the end, the patients are deprived of doctors and also of the benefits of this technology.

\section{CONCLUSION}

- There is a considerable awareness $(91.2 \%)$ of the PCPNDT Act and majority (67.4\%) of the women who wanted a male child was due to family pressure.

- The PCPNDT Act has failed to fulfill its purpose as even though the sex ratio at birth has improved, the child sex ratios have still declined.

- This law was made without taking into account the aspirations of the people of different states and cultures. In a democracy, the will of the people has to be taken into consideration. The law fails to take into consideration the social stigma of no male children in society.

- Wrong direction of focus in the implementation of the Act. The Act should be focused on feticide instead of sex determination.

Too much stress is given to the poor implementation of the PCPNDT act as the main cause of gender disparity, but societal pressures, poverty, illiteracy, unemployment social customs, belief and anti-female attitude are overlooked.

The doctors should not be the only ones made responsible for the gender disparity and hence should not be punished too harshly as they are being today.

From this study, we feel, that the law punishes the technology and does not look into the main cause which is the mentality, that is why it has failed.

The need of the hour is to look into the real factors responsible for this gender disparity and raise the status of females in society.

\section{REFERENCES}

1. Office of the Registrar General and Census Commissioner, India. Provisional Population Totals Paper 1 of 2011 India Series-1. New Delhi: Government of India, 2011.

2. National Rural Health Mission. The Preconception and Prenatal Diagnostic Techniques (Prohibition of Sex-Selection Act, 1994) and Rules with Amendments. New Delhi: Government of India, India:DGHS, 2010-2011

3. Sharmila V, Babu T, Singh D. Knowledge, awareness and attitude about prenatal sex determination, pre-conception and pre-natal diagnostic techniques act among pregnant women in the South Indian union territory of Puducherry. International Journal of Reproduction, Contraception, Obstetrics and Gynecology. 2016 Oct;5(10):3470-3474

4. Mehta S, Acharya A, Meena R, Acharya R, Sharma G. A Study of Attitude, Awareness and Practice on Female Feticide of Pregnant Women in Bikaner of Rajasthan. Journal of Medical Science And clinical Research. 2017 January;05(01):1718517187. 